\title{
Changes in Precipitation Seasonality in West Africa Predicted by RegCM3 and the Impact of Dynamic Vegetation Feedback
}

\author{
Guiling Wang and Clement A. Alo \\ Department of Civil and Environmental Engineering, University of Connecticut, 261 Glenbrook Road, Storrs, CT 06269, USA \\ Correspondence should be addressed to Guiling Wang, gwang@engr.uconn.edu
}

Received 5 May 2011; Accepted 26 September 2011

Academic Editor: Andrea Sealy

Copyright (c) 2012 G. Wang and C. A. Alo. This is an open access article distributed under the Creative Commons Attribution License, which permits unrestricted use, distribution, and reproduction in any medium, provided the original work is properly cited.

\begin{abstract}
Using a regional climate model asynchronously coupled to a dynamic vegetation model, this study examines future climate predictions for the West Africa region and how dynamic vegetation feedback may influence such predictions. Without accounting for the impact of vegetation dynamics, the model predicts a future decrease of annual rainfall over Sahel. Dynamic vegetation feedback reverses this trend, leading to a substantial increase of annual rainfall. Regardless of how vegetation is treated, the predicted future trend of precipitation in the Sahel region follows a specific seasonal pattern, with a decrease during the preand early-monsoon season (May-June and early July) due to the warming-induced enhancement of spring convective barrier and an increase after the monsoon is fully established (typically in July-August-September) due to enhanced moisture import from a warmer ocean. Dynamic vegetation feedback reduces the magnitude of the predicted rainfall reduction in the early season and increases the magnitude of the predicted rainfall increase later in the rainy season. The future decrease of early-season rainfall has significant agronomic implications.
\end{abstract}

\section{Introduction}

Climate variability in West Africa is characterized by a megadrought in the second half of the 20th century and the alternating occurrence of multidecadal dry and wet spells in recent history (e.g., the fluctuation of lake level in [1]). While the role of large-scale oceanic forcing (e.g., warming of the tropical oceans and changes in the interhemispheric temperature gradient) cannot be neglected $[2,3]$, land surface dynamics may have played a critical role in triggering, enhancing, and/or sustaining the megadrought and in regulating the multidecadal climate variability of this regional climate system. In particular, past modeling studies have collectively documented that the climate system in West Africa is highly sensitive to both anthropogenic land cover changes and natural vegetation dynamics, in the past, present, and future [4-8].

Studies on paleoclimate indicated that vegetation feedback plays an important role in sustaining the extended grassland cover during the mid-Holocene and in the subsequent abrupt transition from a green Sahara to a desert later during the mid-Holocene [6, 9-12]. Specifically, vegetation dynamics enhances the response of the West African climate system to changes in solar insolation, leading to the drastic differences in climate and vegetation distribution between mid-Holocene and the present day [10]. For the 20th century climate, Xue and Shukla [4] found that desertification in the Sahel region (in the form of land cover change from natural vegetation to desert) causes a decrease of precipitation that resembles the megadrought observed in the Sahel region from the late 1960s on; Wang and Eltahir [5] found that feedback from natural vegetation dynamics enhances (and sustains) the impact of both oceanic forcing and man-made desertification in causing the 20th century Sahel drought. Feedback due to natural vegetation dynamics also acts as a damper to the climate system, enhancing the multidecadal variability of precipitation in the Sahel region $[1,13-$ 16]. Thus, contributions of vegetation dynamics warrant consideration in simulations of future climate. Paeth et al. [7] carried out regional climate predictions up to the year 2050 forced with future $\mathrm{CO}_{2}$ concentration and land use changes for $\mathrm{A} 1 \mathrm{~B}$ and $\mathrm{B} 1$ emission scenarios and found that 
the simulated climate response in West and Central Africa is primarily dominated by a drought caused by land use changes. Although the land use change signal may become less dominant if the prediction was done for a higher $\mathrm{CO}_{2}$ concentration (e.g., for the A2 scenario or for a later stage of the century), their study clearly demonstrated the important role of land use as a climate change forcing. Incorporating natural vegetation dynamics into a regional climate model used for future prediction, Alo and Wang [8] found that natural vegetation feedback leads to a significant increase of future precipitation in most of West Africa.

The strong water dependency of the socioecological system in West Africa and the fragility of food security in the region make it extremely vulnerable to climate changes. However, predictions for precipitation changes in the 2 nd half of the 21st century (mostly from atmosphere-ocean general circulation models (AOGCMs)) in the West and North Africa are highly model dependent and lack any general consensus [17]. To specifically address this uncertainty in future predictions, Patricola and Cook [18] generated an ensemble of future predictions for this region using a regional climate model driven with seas surface temperature and lateral boundary conditions from nine AOGCMs and found a relatively good agreement among different ensemble members despite the lack of consensus among the driving AOGCMs. For West Africa, their regional model predicts a generally wetter condition with the exception of a midseason drought in June and July.

Crop productivity in the Sahel is limited not only by the amount of precipitation during the rainy season but more importantly by the length of the growing/rainy season. In most of the Sahel belt, the length of the rainy season is less than three months. Although the preonset rainfall can amount to a few millimeters on some days, it is scattered and cannot provide reliable source of water for agriculture. The optimal planting time for crops is found to occur within a few days of the large-scale monsoon onset time [19], which is defined as the sudden shift of the ITCZ maximum from around $5 \mathrm{~N}$ to around $10 \mathrm{~N}$ [20]. Based on projections from multiple general circulation models (GCMs), it was found that most monsoon systems in the 21st century (West Africa monsoon included) will experience a change in precipitation seasonality, with a precipitation decrease in spring/early summer and an increase in late summer/early fall [21, 22]. However, due to the coarse spatial resolution used, most GCMs cannot simulate the sudden onset of the West African monsoon, an important feature of the seasonal variability of this regional climate [23]. Regional climate models (RCMs) have a much better performance in capturing the sudden monsoon onset [24]. Given the strong latitudinal gradient of precipitation in West Africa and the importance of monsoon onset for West African agriculture, it is necessary to assess future changes of precipitation seasonality using RCMs that have a finer spatial resolution than most GCMs.

While still uncommon among the IPCC projections, some GCMs have included dynamic vegetation in future prediction experiments $[25,26]$. The inclusion of dynamic vegetation in RCMs however is still at a very early stage [27] and has not been applied to climate predictions. In a preliminary study asynchronously linking a regional climate model with a dynamic vegetation model, Alo and Wang [8] demonstrated that future vegetation in West Africa will become denser, but the vegetation composition will shift towards more drought deciduous trees and grass at the expense of evergreen trees. Compared with the prediction assuming static vegetation, vegetation dynamics acts to increase precipitation amount over most of West Africa except for the narrow band along the coast. This current study is based on the same set of experiments used in Alo and Wang [8], but focuses on changes in precipitation seasonality and monsoon onset in West Africa and how vegetation dynamics may influence them.

\section{Model and Experimental Design}

The model used is the International Centre for Theoretical Physics (ICTP) regional climate model (RegCM3) asynchronously coupled to the National Center for Atmospheric Research (NCAR) Community Land Model's Dynamic Global Vegetation Model (CLM-DGVM). CLM-DGVM [26] simulates biogeophysical, biogeochemical, and ecosystem dynamics processes at the land surface. Its biogeophysical submodel is CLM3.0 [28, 29] and the biogeochemical and vegetation dynamics submodels are based on the LundPotsdam-Jena Dynamic Global Vegetation Model (LPJDGVM) [30], with a plant phenology scheme modified based on the Integrated Biosphere Simulator (IBIS) [31]. RegCM3 [32] is a limited-area model with a terrainfollowing $\sigma$-pressure vertical coordinate system and uses the Biosphere-Atmosphere-Transfer Scheme (BATS1E) [33] as its land surface biogeophysical submodel. We configure RegCM3 at $50 \mathrm{~km}$ horizontal resolution over a domain spanning approximately $12^{\circ} \mathrm{S}-24^{\circ} \mathrm{N}$ and $24^{\circ} \mathrm{W}-30^{\circ} \mathrm{E}$, with 18 levels in the vertical direction. Among the three different convection parameterizations in RegCM3, the MIT-Emanuel scheme [34] option is chosen based on performance over the study domain. RegCM3 has been shown to perform well in its simulation of precipitation over West Africa [35-37].

In the asynchronous coupling approach, CLM3-DGVM is run at the same spatial and temporal resolutions and over the same domain as RegCM3, but the two models alternate. Specifically, RegCM3 is run for one year with an initial state of vegetation, and the resulting atmospheric forcing for each time step is saved; this saved atmospheric forcing is then read into CLM3-DGVM to drive a transient vegetation simulation for one year, producing an updated vegetation state for RegCM3. This iteration continues through the duration of the simulation. Note that this approach allows the simulation of transient vegetation dynamics, which is different from most other asynchronously coupled models in which an equilibrium vegetation state is predicted for each iteration based on the climate state simulated during that iteration $[38,39]$.

The asynchronously coupled RegCM3/CLM3-DGVM model is used to conduct two simulations, a presentday climate-vegetation run "Present" and a future climatevegetation run "Future". In addition, a future climate simulation "Future_nv" is conducted using RegCM3 but with 
vegetation fixed at the present-day state (i.e., prescribed based on output from "Present"), to facilitate quantifying the contribution from dynamic vegetation feedback. Based on this design, climate and hydrological differences between "Future_nv" and "Present" result from the radiative and physiological effects of elevated $\mathrm{CO}_{2}$, differences between "Future" and "Future_nv" represent the contribution from structural vegetation feedback, and differences between "Future" and "Present" result from the combination of $\mathrm{CO}_{2}$ radiative and physiological effects and vegetation structural feedback. Each of the simulations is 15-year long, and the first five years of data is discarded as model spinup. The initial and lateral boundary conditions as well as sea surface temperature for RegCM3 are provided by the NCAR global climate system model CCSM3's IPCC AR4 simulations. Although regional climate models are known to be sensitive to lateral boundary conditions, Patricola and Cook [18] found a relatively high level of consensus among predictions by a regional climate model driven with nine different GCMs despite the lack of consensus among these nine driving GCMs. The use of lateral boundary conditions from a single GCM in this study is therefore not expected to a cause too high level of uncertainty. The period 1979-1993 from the CCSM3 20C3M simulation is used for the present-day climate, and 2079-2093 from the CCSM3 SRESA1B experiment is used for the future climate. $\mathrm{CO}_{2}$ concentration is set to $356 \mathrm{ppmv}$ for the present-day climate and $720 \mathrm{ppmv}$ for future. Initial vegetation conditions for the asynchronously coupled RegCM3/CLM-DGVM runs are derived from CLM-DGVM long-term simulations forced with the 1979-1993 (2079-2093) climate from the CCSM3 20C3M (SRESAIB) output under corresponding $\mathrm{CO}_{2}$ concentration, interpolated to the RegCM3 spatial resolution. Based on the results of Alo and Wang [8] who examined the vegetation distribution and future changes simulated by CLM-DGVM driven with climate forcing from eight GCMs, the vegetation distribution corresponding to the CCSM3 climate is the most realistic among the eight.

\section{Results}

When driven by initial and lateral boundary conditions from CCSM3, the asynchronously coupled RegCM3/CLM3DGVM simulates the present-day precipitation pattern and vegetation distribution reasonably well in comparison with observations. Details about model performance in simulating the regional climate and vegetation are provided in Alo and Wang [8]. The focus of the following analysis is on future changes of precipitation, its seasonal cycle, the West African monsoon onset, and on the impact of vegetation dynamics in these predictions.

In response to the radiative and physiological effects of elevated atmospheric $\mathrm{CO}_{2}$, RegCM3 without accounting for vegetation dynamics predicts a decrease of annual rainfall in most of West Africa, with an increase over a narrow coastal band and the eastern Sahel region (Figure 1(a)). This decrease may be partly related to the lower stomatal conductance at higher $\mathrm{CO}_{2}$ concentration, which potentially suppresses transpiration therefore local moisture supply.
When the dynamic vegetation feedback is included, the predicted future drought signal is limited to part of the Guinea Coast band only, and annual rainfall is predicted to increase or remain about the same over most of the Sahel (Figure 1(b)). The feedback from dynamic vegetation leads to a substantial increase of precipitation over most of the model domain except for the narrow band along the coast (Figure 1(c)). These changes of precipitation are accompanied by a northward expansion of grassland in the north and increase of broadleaf drought-deciduous tree coverage in the south at the expense of evergreen trees (Figure 2). Compared with the future vegetation cover changes predicted by CLM3-DGVM driven directly with the CCSM3 A1B climate projection [40], the changes predicted by the RegCM3/CLM3-DGVM system as shown in Figure 2 are significantly larger in magnitude (and therefore faster in rate). Across most of West Africa, vegetation is predicted to become denser (regardless of how the vegetation distribution shifts) as a result of the $\mathrm{CO}_{2}$ fertilization effects dominating over other factors (results not shown; see Alo and Wang [8] for details).

Similar to present-day observations (e.g., [41]), both the present-day and future climates in the model (black and red contour lines in Figure 3) are characterized by substantial amounts of rain during the preonset season followed by the abrupt monsoon onset in late June. Following Sultan and Janicot [20], here we define the monsoon onset as the timing of the sudden shift of rain maximum from $5-6^{\circ} \mathrm{N}$ to $8-10^{\circ} \mathrm{N}$. The monsoon onset is characterized by an abrupt increase of rainfall at about $10^{\circ} \mathrm{N}$ in late June, which is very apparent from the contour lines in Figure 3. The monsoon rainfall peaks in August and gradually retreats afterwards, which are also consistent with present-day observations of the monsoon characteristics [20].

The predicted future precipitation changes follow a specific seasonal pattern. Over the Sahel region where vegetation growth and crop production are limited by water, future precipitation will decrease early in the rainy season (during late spring/early summer) and increase later (during late summer and early fall) (shading in Figure 3). Despite the rainfall decrease during the preonset season, future rainfall will become more abundant and penetrates further inland after the monsoon is fully developed. This seasonal pattern is similar regardless of whether dynamic vegetation feedback is accounted for. However, vegetation dynamics does make a difference in the magnitude of such changes. Without accounting for vegetation feedback (Figure 3(a)), rainfall is predicted to decrease substantially (by more than 60\% in some areas) during spring and early summer across the region, with only minor increase later on. The decrease of rainfall occurs to both the preonset rain and during the peak monsoon. When vegetation dynamics is included (Figure 3(b)), the predicted future decrease of rainfall is much smaller and limited to primarily the preonset rain, with a much larger increase during the peak monsoon and the retreating phase.

These predicted changes in precipitation seasonal cycle in the Sahel region are consistent with previous findings concerning most monsoon systems based on GCM ensembles 


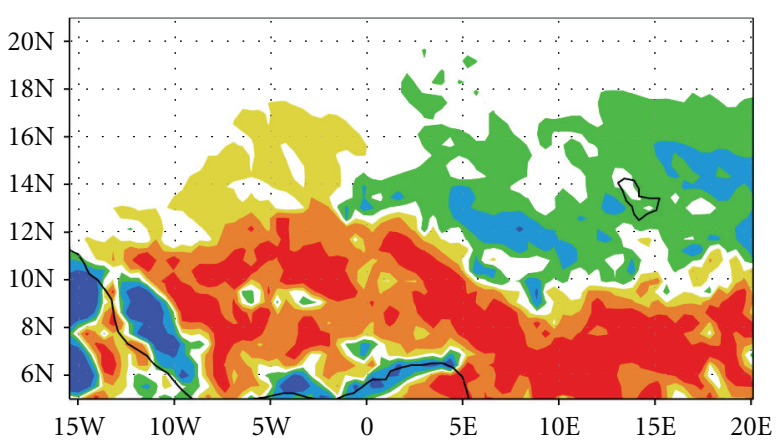

(a) Without dynamic vegetation

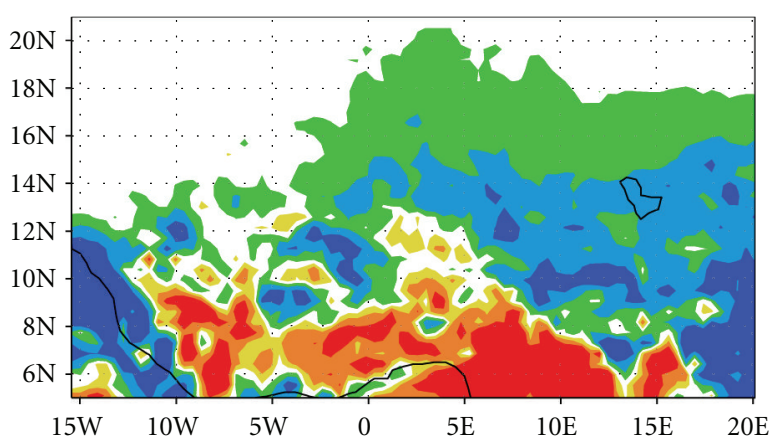

(b) With dynamic vegetation

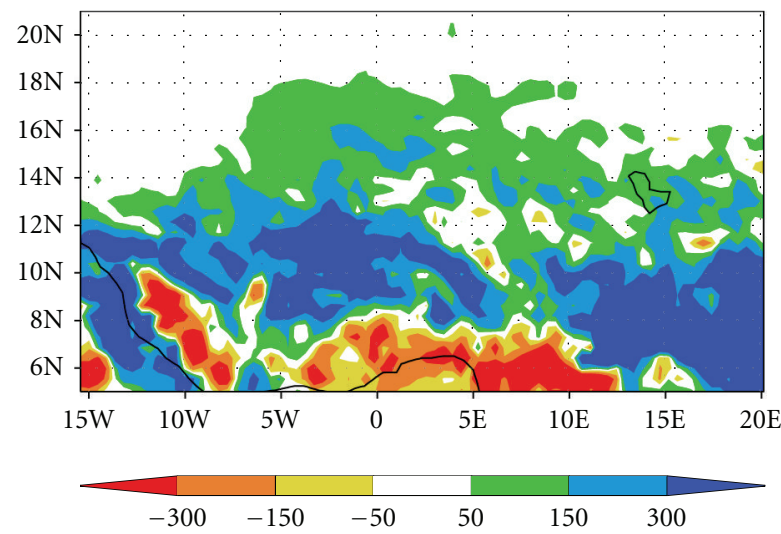

(c) Impact of dynamic vegetation

FIGURE 1: Changes in annual precipitation (in $\mathrm{mm}$ ) simulated without dynamic vegetation (i.e., "Future_nv"——Present"), with dynamic vegetation (i.e., "Future"— "Present"), and the contribution due to dynamic vegetation feedback (i.e., "Future"—“Future—nv").

$[21,22]$. Seth et al. [21] suggested that such changes might be related to the enhancement of spring convective barrier due to warming-induced drought. Figure 4 presents the predicted future changes in troposphere stability, where the troposphere stability is represented by the moist static energy difference between $200 \mathrm{mb}$ and $850 \mathrm{mb}$ following Seth et al. [21]. A strong increase of troposphere stability is evident in the Sahel region during all seasons except for the active monsoon season when the troposphere stability is weakened. It is apparent that future climate features a stronger contrast in troposphere stability between the wet and dry seasons. Feedback from vegetation dynamics is found to reduce the future troposphere stability and favor more precipitation across all seasons, probably due to the increased specific humidity caused by enhancement of evapotranspiration by denser vegetation.

The changes in precipitation amount and seasonal cycle do not seem to be related to changes in the timing of the monsoon circulation. Using $12^{\circ} \mathrm{N}$ and $15^{\circ} \mathrm{N}$ as examples, Figure 5 shows the daily time series of zonally averaged wind and precipitation. Despite the strong decrease in the preonset precipitation, there is no clear evidence for a delay in the timing of zonal or meridional wind reversal. The timing of the wind reversal in the model is remarkably robust against future climate changes and against how vegetation is treated. To define the monsoon onset following the established approach of Sultan and Janicot [20], that is, the timing of a sudden change in the slope of precipitation increase, Figure 6 also shows the 11 -day running mean of precipitation at $10^{\circ} \mathrm{N}$. The crosses in Figure 6 indicate the approximate timing for monsoon onset. The model predicts a five-day delay in future monsoon onset without accounting for the impact of vegetation dynamics, and dynamic vegetation feedback reduces this delay to two days. As evident in Figure 6, a slight delay of monsoon retreat might be expected, but the magnitude of such delay is very small.

Despite the decrease of preonset rainfall and the slightly delayed monsoon onset, atmospheric specific humidity increases over land after the monsoon onset, as a result of moisture import from over the ocean where warminginduced increase of evaporation leads to a significant increase of atmospheric moisture (Figure 7). This increase of moisture partly contributes to the enhanced precipitation and the weakening of troposphere stability after the monsoon is fully established (Figures 3 and 4). During the peak monsoon season (e.g., August), the ocean-to-land gradient of moist static energy in the lower troposphere is predicted to become much stronger in the future, and the peak of the moist static energy is located further inland in the case with dynamic vegetation feedback (Figure 8 ). This, according to Eltahir and Gong [42], suggests a stronger monsoon circulation and a more northward penetration of the monsoon rainfall, consistent with results in Figures 3 and 5. 


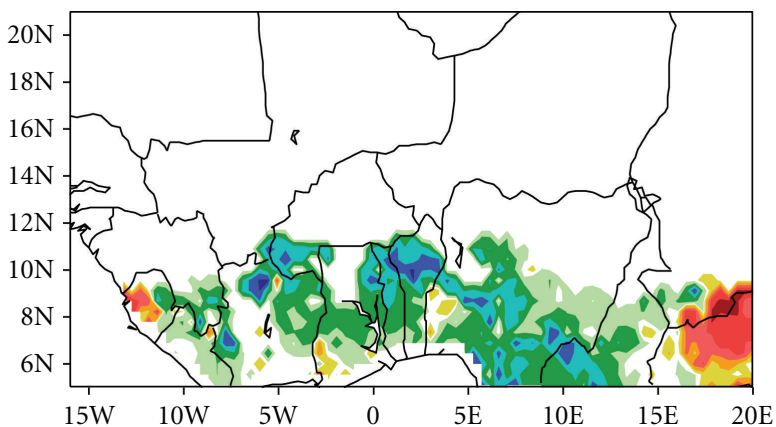

(a) Evergreen trees

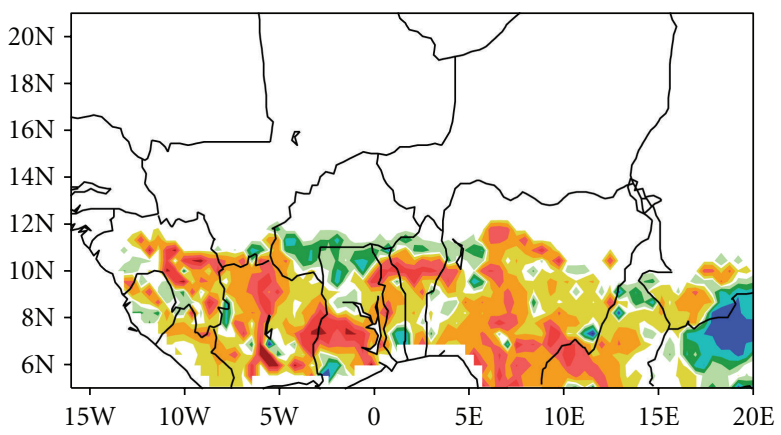

(b) Deciduous trees

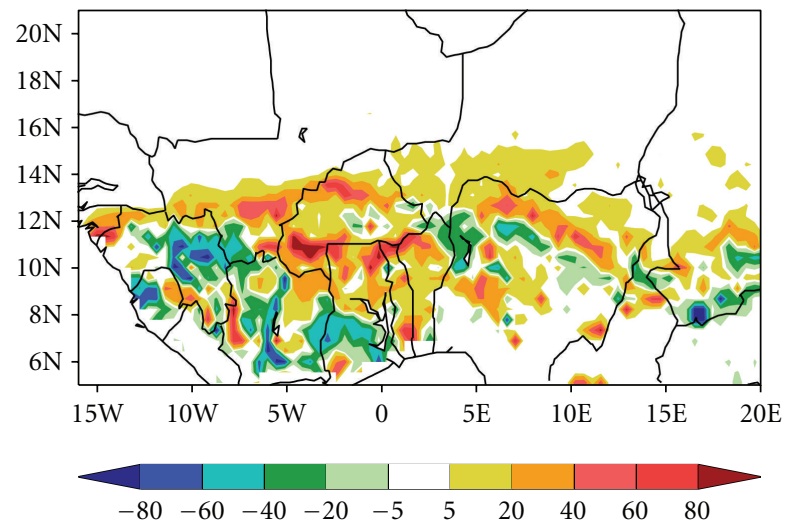

(c) Grasses

Figure 2: Changes in fractional coverage of vegetation types ("Future"- "Present") as percent of vegetated portion of grid cell.

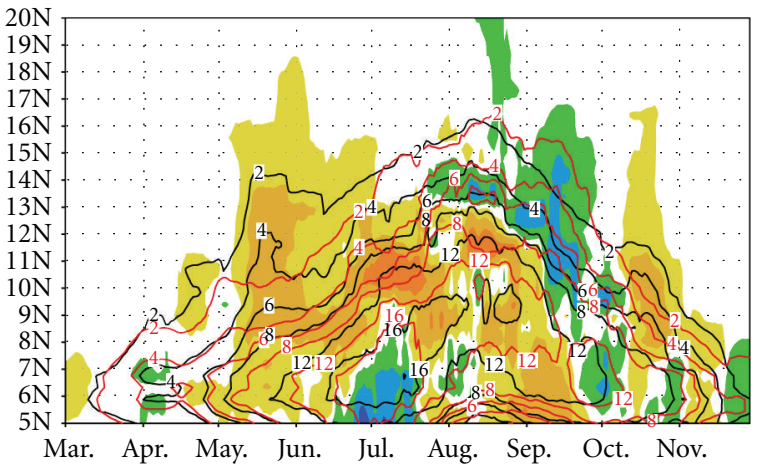

(a) Without dynamic vegetation

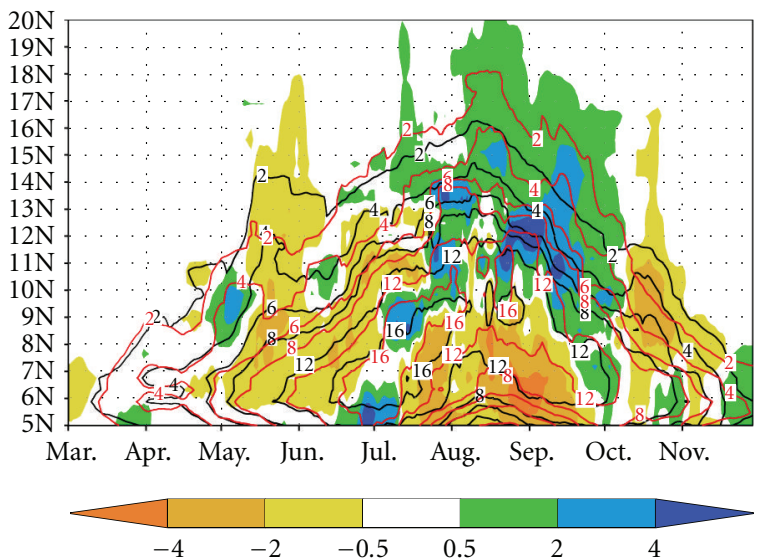

(b) With dynamic vegetation

Figure 3: Predicted daily precipitation changes (color shading, in $\mathrm{mm} /$ day) during March-November, with variability more frequent than 11 days filtered out. The contour lines represent the 11-day filtered daily precipitation during 1984-1993 (black) and during 2084-2093 (red).

\section{Summary and Discussion}

Using the regional climate model RegCM3 driven with lateral boundary conditions from the NCAR CCSM3 based on the SRES A1b scenario, this study examines future climate predictions for the West Africa region and how dynamic vegetation feedback may influence such predictions. Major findings are summarized in the following.
(1) Vegetation dynamics reverses the predicted future trend of annual precipitation in the Sahel region, from a drying trend to a wet trend. Over the Guinea Coast region, vegetation dynamics has little impact on future precipitation predictions.

(2) The predicted future trend of precipitation in the Sahel region follows a specific seasonal pattern, with 


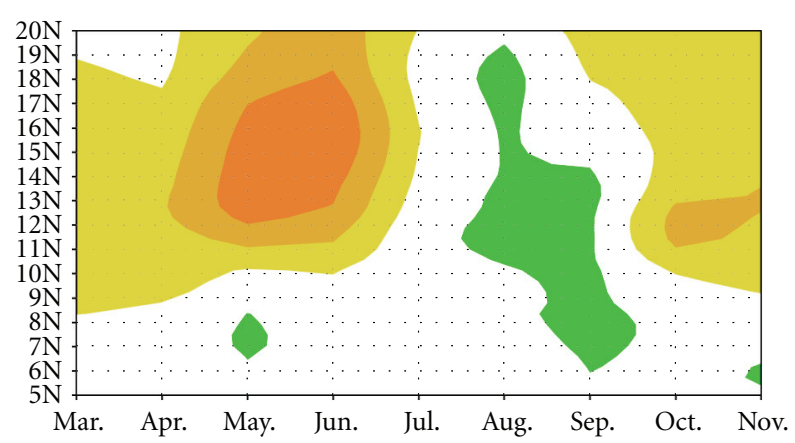

(a) Without dynamic vegetation

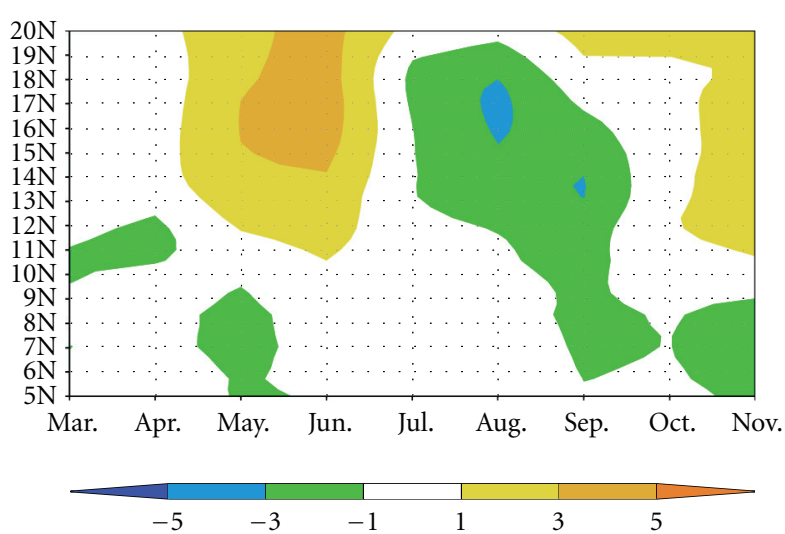

(b) With dynamic vegetation

Figure 4: Changes in the troposphere stability between 1984-1993 and 2084-2093, averaged over $5^{\circ} \mathrm{W}-5^{\circ} \mathrm{E}$, simulated without dynamic vegetation (a) and with dynamic vegetation (b). The troposphere stability is represented by the moist static energy difference between $200 \mathrm{mb}$ and $850 \mathrm{mb}\left(\mathrm{MSE}_{200}-\mathrm{MSE}_{850}\right)$.

a decrease during the preonset and early monsoon seasons and an increase after the monsoon is fully developed. Dynamic vegetation feedback reduces the magnitude of the predicted rainfall reduction early in the season and increases the magnitude of the predicted rainfall increase later in the season.

(3) The decrease of preonset rainfall is related to the warming-induced enhancement of convective barrier during spring, while the increase of precipitation during the peak monsoon results from the increased specific humidity as the monsoon circulation brings more moisture from a warmer ocean.

(4) Despite the substantial decrease of preonset rainfall in most of West Africa, the model predicts no detectable delay in the timing of the monsoon circulation (e.g., timing of wind reversal) and only a slight (if any) delay in the onset of the monsoon rainfall. This statement holds regardless of how vegetation is treated.

Druyan [17] reviewed ten major papers on future precipitation prediction in this region and found no consensus among different models regarding future precipitation trend. There is some similarity between our results and the study of Patricola and Cook [18] in that future precipitation trend differs between different stages of the monsoon development, but the two differ significantly for the pre- and earlymonsoon stages. The simulated robust increase of precipitation in this study during the fully developed monsoon phase is consistent with the finding of Fontaine et al. [43]. Fontaine et al. [43] focused on the July-August-September (JAS) precipitation for the Sahel region and found that a vast majority of the $12 \mathrm{GCMs}$ examined predict an increase of JAS precipitation for the Sahel region. The increase of precipitation during JAS however does not necessarily mean rainfall excess for plant growth. As our results indicate, the future trend of precipitation during the preonset season can be very different from the JAS season. The decrease of rainfall in the preonset season found in our study can lead to a delayed and in some areas (e.g., south of $12^{\circ} \mathrm{N}$ ) shortened growing season. North of $12^{\circ} \mathrm{N}$, however, the increase of future precipitation is dominant and the growing season may become longer.

The strong increase of precipitation across the rainy season north of $12^{\circ} \mathrm{N}$ is consistent with the expansion of grass cover in Figure 2. While the rainfall excess supports more growth, the increased grass cover lowers the surface albedo and enhances evapotranspiration, both of which favor more precipitation over this highly sensitive region. The vegetation feedback can take place both at the intraseasonal time scale and over interannual time scale. At the glassland region, it is more straightforward at the intraseasonal time scale through the above-ground vegetative response. At the interannual time scale, this feedback can be facilitated by the root system of perennial grasses and/or seed bank of annual grasses, with the first flush of vegetation growth at the beginning of the rainy season supported by carbon storage in the roots resulting from previous year's carbon production or seeds produced in the previous year. In the real world, both mechanisms can support inter-annual land memory in the Sahel region found in the Normalized Difference Vegetation Index (NDVI) data [44]. In the model used here, vegetation feedback at the inter-annual time sale over grassland region relies on roots of perennial grass, as annual grass is not simulated in the model.

The use of different land surface biogeophysical schemes (BATS versus CLM3) creates a certain level of inconsistency between RegCM3 and CLM3-DGVM, and such inconsistency is intrinsic to all asynchronous coupling approaches (e.g., $[38,39,45,46])$. This also creates the need for mapping between the BATS vegetation categorization and 


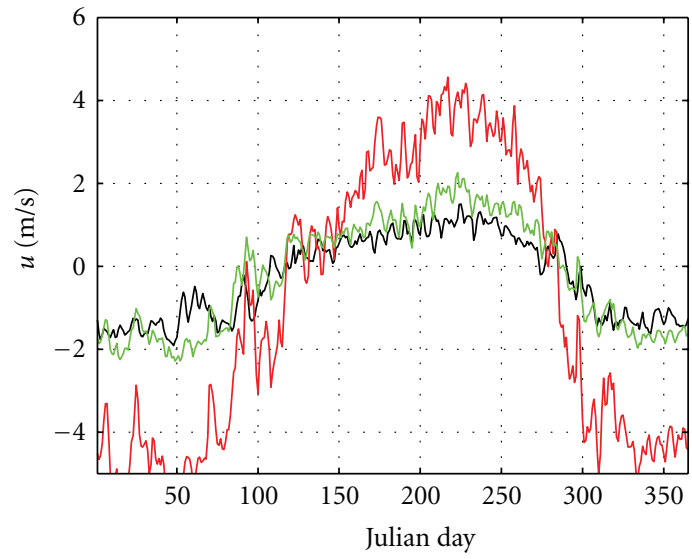

(a) Zonal wind at $12^{\circ} \mathrm{N}$

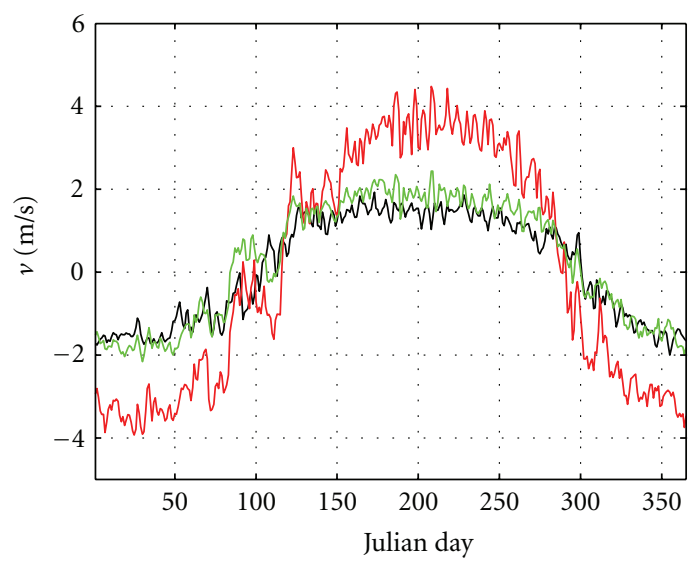

(b) Meridional wind at $12^{\circ} \mathrm{N}$

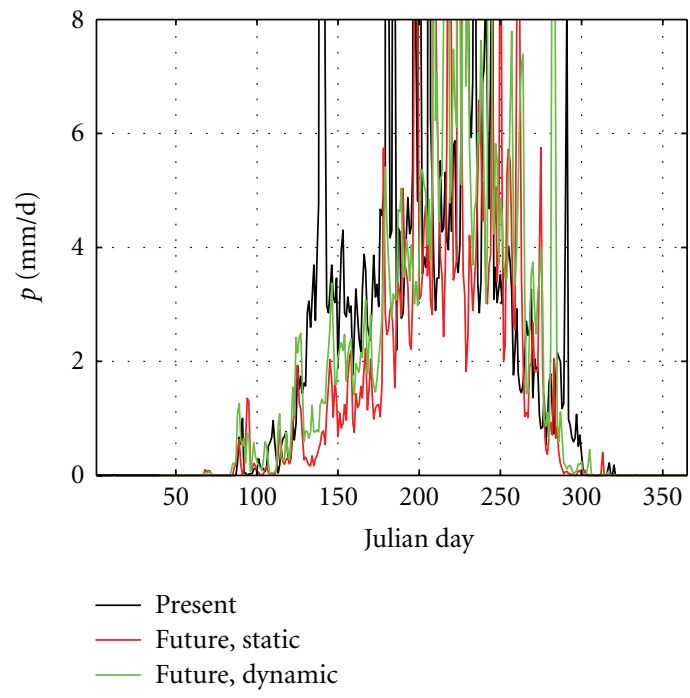

(c) Precipitation at $12^{\circ} \mathrm{N}$

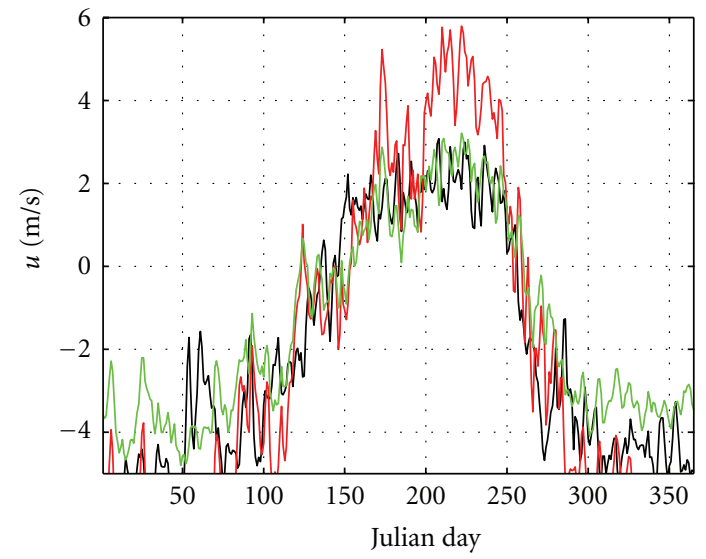

(d) Zonal wind at $15^{\circ} \mathrm{N}$

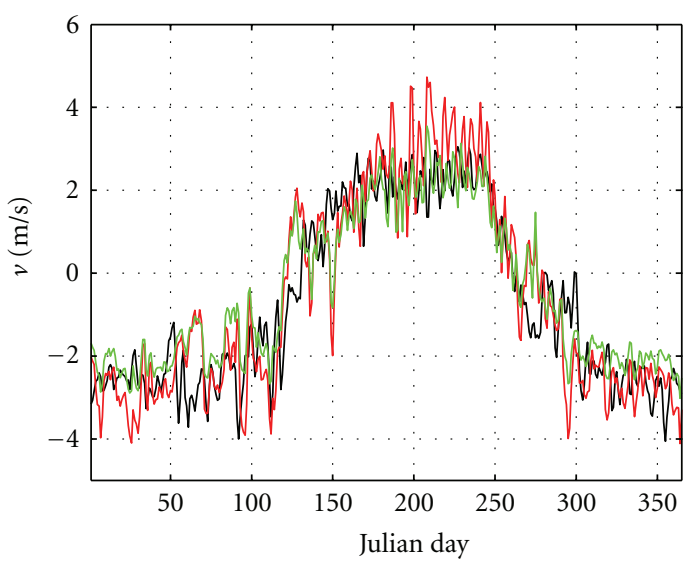

(e) Meridional wind at $15^{\circ} \mathrm{N}$

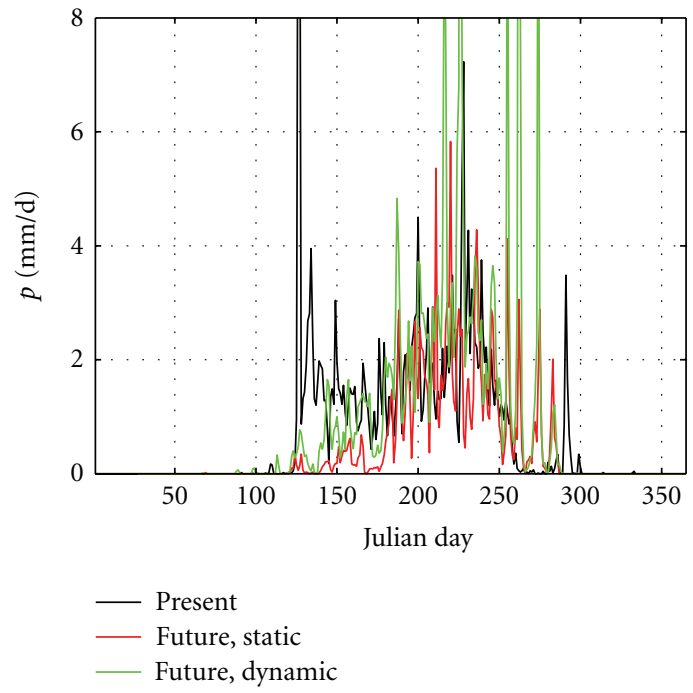

(f) Precipitation at $15^{\circ} \mathrm{N}$

FIGURE 5: Climatology of daily wind and daily rainfall at $12^{\circ} \mathrm{N}$ and $15^{\circ} \mathrm{N}$, averaged over $5^{\circ} \mathrm{W}-5^{\circ} \mathrm{E}$. 


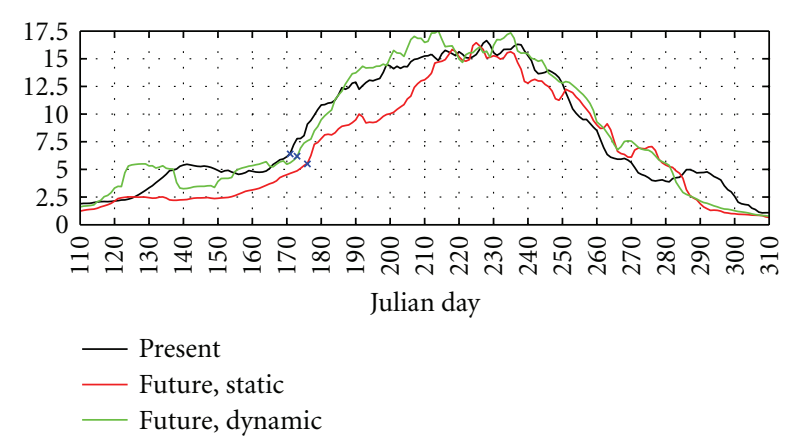

FIGURE 6: 11-day running mean of the zonally averaged daily precipitation $(\mathrm{mm})$ at $10^{\circ} \mathrm{N}$, with the monsoon onset approximately marked by " $\mathrm{x}$ ".

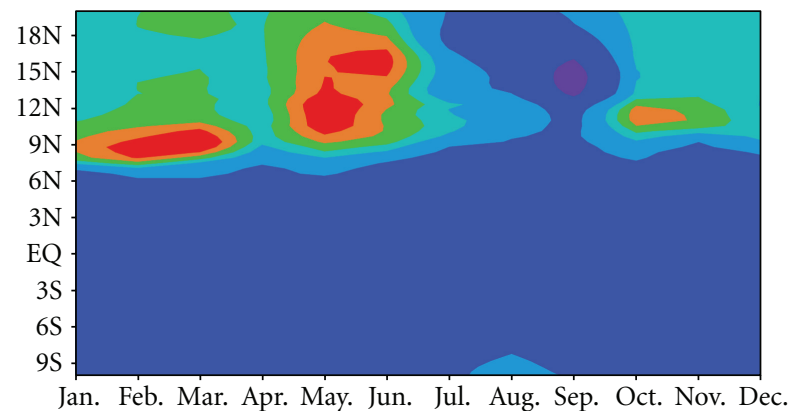

(a) Without dynamic vegetation
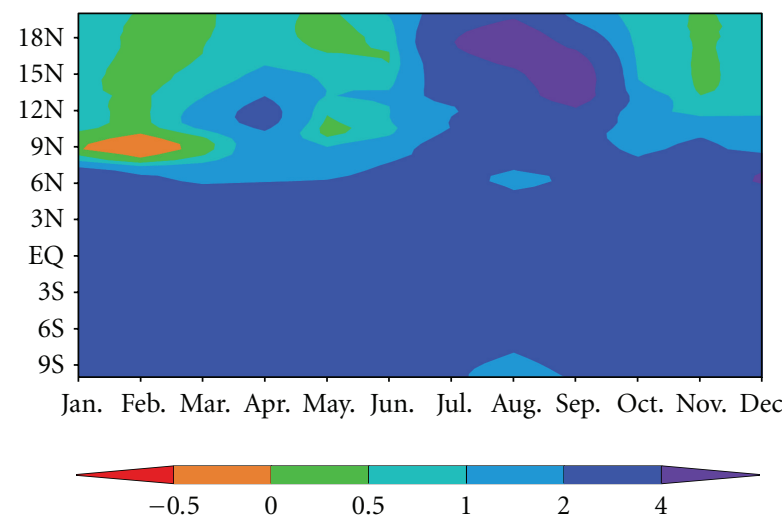

(b) With dynamic vegetation

FIgURE 7: Monthly mean changes in surface specific humidity $(\mathrm{g} / \mathrm{kg})$, averaged over $5^{\circ} \mathrm{W}-5^{\circ} \mathrm{E}$.

the vegetation plant functional types simulated by CLMDGVM. It is not clear how this inconsistency may have influenced the results, especially results on the modifications of future prediction by vegetation dynamics. To address this uncertainty, we are currently developing a synchronously coupled version of the model, which involves incorporating vegetation dynamics into the latest version of the regional climate model RegCM4 [47] that uses CLM3.5 (as opposed to BATS in RegCM3) as its land surface model.

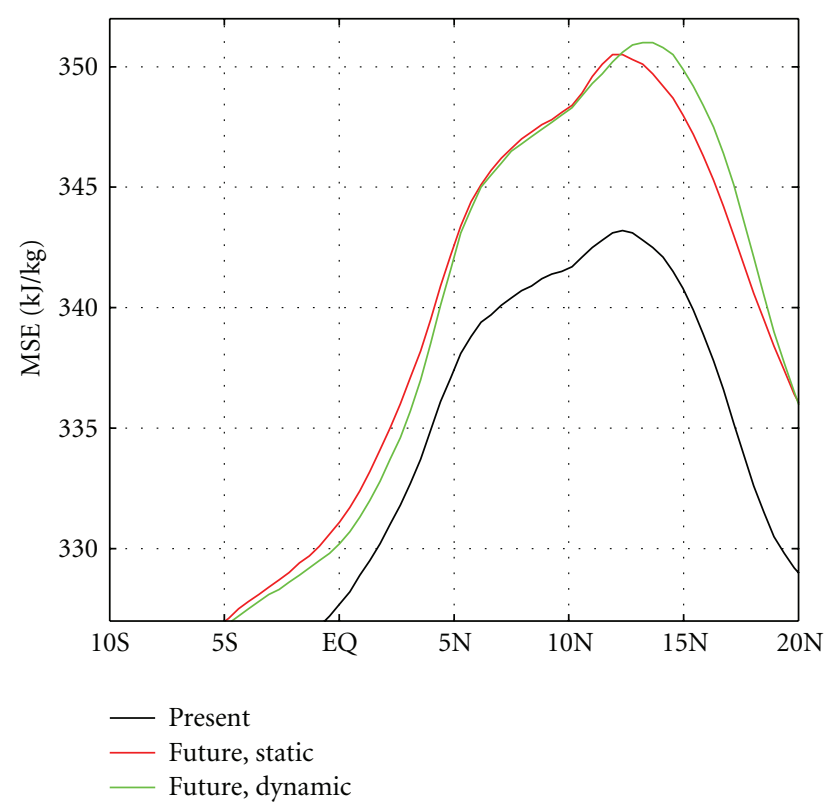

FIGURE 8: Low-level moist static energy averaged during the peak monsoon month August and over $5^{\circ} \mathrm{W}-5^{\circ} \mathrm{E}$.

\section{Acknowledgment}

This work is supported by funding from the National Science Foundation (NSF) under Agreements ATM-0531485 and AGS-1063986.

\section{References}

[1] G. Wang and E. A. B. Eltahir, "Role of vegetation dynamics in enhancing the low-frequency variability of the Sahel rainfall," Water Resources Research, vol. 36, no. 4, pp. 1013-1021, 2000.

[2] A. Giannini, R. Saravanan, and P. Chang, "Oceanic forcing of sahel rainfall on interannual to interdecadal time scales," Science, vol. 302, no. 5647, pp. 1027-1030, 2003.

[3] M. Biasutti, I. M. Held, A. H. Sobel, and A. Giannini, "SST forcings and Sahel rainfall variability in simulations of the twentieth and twenty-first centuries," Journal of Climate, vol. 21, no. 14, pp. 3471-3486, 2008.

[4] Y. Xue and J. Shukla, "The influence of land surface properties on Sahel climate. Part I: desertification," Journal of Climate, vol. 6, no. 12, pp. 2232-2245, 1993.

[5] G. Wang and E. A. B. Eltahir, "Ecosystem dynamics and the Sahel drought," Geophysical Research Letters, vol. 27, no. 6, pp. 795-798, 2000.

[6] C. M. Patricola and K. H. Cook, "Atmosphere/vegetation feedbacks: a mechanism for abrupt climate change over northern Africa," Journal of Geophysical Research D, vol. 113, no. 18, Article ID D18102, 2008.

[7] H. Paeth, K. Born, R. Girmes, R. Podzun, and D. Jacob, "Regional climate change in tropical and Northern Africa due to greenhouse forcing and land use changes," Journal of Climate, vol. 22, no. 1, pp. 114-132, 2009.

[8] C. A. Alo and G. Wang, "Role of dynamic vegetation in regional climate predictions over Western Africa," Climate Dynamics, vol. 35, no. 5, pp. 907-922, 2010. 
[9] M. Claussen, C. Kubatzki, V. Brovkin, A. Ganopolski, P. Hoelzmann, and H. J. Pachur, "Simulation of an abrupt change in Saharan vegetation in the mid-Holocene," Geophysical Research Letters, vol. 26, no. 14, pp. 2037-2040, 1999.

[10] M. M. Irizarry-Ortiz, G. Wang, and E. A. B. Eltahir, "Role of the biosphere in the mid-Holocene climate of West Africa," Journal of Geophysical Research D, vol. 108, no. 2, pp. 5-15, 2003.

[11] Z. Liu, Y. Wang, R. Gallimore, M. Notaro, and I. C. Prentice, "On the cause of abrupt vegetation collapse in North Africa during the Holocene: climate variability vs. vegetation feedback," Geophysical Research Letters, vol. 33, no. 22, Article ID L22709, 2006.

[12] M. Notaro, Y. Wang, Z. Liu, R. Gallimore, and S. Levis, "Combined statistical and dynamical assessment of simulated vegetation-rainfall interactions in North Africa during the mid-Holocene," Global Change Biology, vol. 14, no. 2, pp. 347368, 2008.

[13] N. Zeng, J. D. Neelin, K. M. Lau, and C. J. Tucker, "Enhancement of interdecadal climate variability in the Sahel by vegetation interaction," Science, vol. 286, no. 5444, pp. 1537-1540, 1999.

[14] G. Wang, E. A. B. Eltahir, J. A. Foley, D. Pollard, and S. Levis, "Decadal variability of rainfall in the Sahel: results from the coupled GENESIS-IBIS atmosphere-biosphere model," Climate Dynamics, vol. 22, no. 6-7, pp. 625-637, 2004.

[15] C. Delire, J. A. Foley, and S. Thompson, "Long-tern variability in a coupled atmosphere-biosphere model," Journal of Climate, vol. 17, no. 20, pp. 3947-3959, 2004.

[16] C. Delire, N. de Noblet-Ducoudré, A. Sima, and I. Gouirand, "Vegetation dynamics enhancing long-term climate variability confirmed by two models," Journal of Climate, vol. 24, no. 9, pp. 2238-2257, 2011.

[17] L. M. Druyan, "Studies of 21st-century precipitation trends over West Africa," International Journal of Climatology, vol. 31, no. 10, pp. 1415-1424, 2011.

[18] C. M. Patricola and K. H. Cook, "Northern African climate at the end of the twenty-first century: an integrated application of regional and global climate models," Climate Dynamics, vol. 35, no. 1, pp. 193-212, 2010.

[19] B. Sultan, C. Baron, M. Dingkuhn, B. Sarr, and S. Janicot, "Agricultural impacts of large-scale variability of the West African monsoon," Agricultural and Forest Meteorology, vol. 128, no. 1-2, pp. 93-110, 2005.

[20] B. Sultan and S. Janicot, "The West African monsoon dynamics. Part II: the "preonset" and "onset" of the summer monsoon," Journal of Climate, vol. 16, no. 21, pp. 3407-3427, 2003.

[21] A. Seth, S. A. Rauscher, M. Rojas, A. Giannini, and S. J. Camargo, "Enhanced spring convective barrier for monsoons in a warmer world? A letter," Climatic Change, vol. 104, pp. 403-414, 2011.

[22] M. Biasutti and A. H. Sobel, "Delayed Sahel rainfall and global seasonal cycle in a warmer climate," Geophysical Research Letters, vol. 36, no. 23, Article ID L23707, 2009.

[23] Y. Xue, F. de Sales, W. K. M. Lau et al., "Intercomparison and analyses of the climatology of the West African Monsoon in the West African Monsoon Modeling and Evaluation project (WAMME) first model intercomparison experiment," Climate Dynamics, vol. 35, no. 1, pp. 3-27, 2010.

[24] L. M. Druyan, J. Feng, K. H. Cook et al., "The WAMME regional model intercomparison study," Climate Dynamics, vol. 35, no. 1, pp. 175-192, 2010.
[25] P. M. Cox, R. A. Betts, C. D. Jones, S. A. Spall, and I. J. Totterdell, "Acceleration of global warming due to carboncycle feedbacks in a coupled climate model," Nature, vol. 408, no. 6809, pp. 184-187, 2000.

[26] G. Bala, K. Caldeira, A. Mirin, M. Wickett, C. Delire, and T. J. Phillips, "Biogeophysical effects of $\mathrm{CO}_{2}$ fertilization on global climate," Tellus, Series B, vol. 58, no. 5, pp. 620-627, 2006.

[27] J. M. Winter, J. S. Pal, and E. A. B. Eltahir, "Coupling of integrated biosphere simulator to regional climate model version 3," Journal of Climate, vol. 22, no. 10, pp. 2743-2757, 2009.

[28] Y. Dai, X. Zeng, R. E. Dickinson et al., "The common land model," Bulletin of the American Meteorological Society, vol. 84, no. 8, pp. 1013-1023, 2003.

[29] K. Oleson, Y. Dai, G. B. Bonan et al., "Technical description of the community land model (CLM)," NCAR Technical Note TN-461+STR, 2004.

[30] S. Sitch, B. Smith, I. C. Prentice et al., "Evaluation of ecosystem dynamics, plant geography and terrestrial carbon cycling in the LPJ dynamic global vegetation model," Global Change Biology, vol. 9, no. 2, pp. 161-185, 2003.

[31] C. J. Kucharik, J. A. Foley, C. Delire et al., "Testing the performance of a dynamic global ecosystem model: water balance, carbon balance, and vegetation structure," Global Biogeochemical Cycles, vol. 14, no. 3, pp. 795-825, 2000.

[32] J. S. Pal, F. Giorgi, X. Bi et al., "Regional climate modeling for the developing world: the ICTP RegCM3 and RegCNET," Bulletin of the American Meteorological Society, vol. 88, no. 9, pp. 1395-1409, 2007.

[33] R. E. Dickinson, A. Henderson-Sellers, and P. J. Kennedy, "Biosphere-atmosphere transfer scheme (BATS) version 1e as coupled to the NCAR community climate model," NCAR Tech. Note/TN-387+STR, 1993.

[34] K. A. Emanuel, "A scheme for representing cumulus convection in large-scale models," Journal of the Atmospheric Sciences, vol. 48, no. 21, pp. 2313-2335, 1991.

[35] G. S. Jenkins, A. T. Gaye, and B. Sylla, "Late 20th century attribution of drying trends in the Sahel from the regional climate model (RegCM3)," Geophysical Research Letters, vol. 32, no. 22, Article ID L22705, pp. 1-4, 2005.

[36] E. A. Afiesimama, J. S. Pal, B. J. Abiodun, W. J. Gutowski, and A. Adedoyin, "Simulation of West African monsoon using the RegCM3. Part I: model validation and interannual variability," Theoretical and Applied Climatology, vol. 86, no. 1-4, pp. 2337, 2006.

[37] J. B. Omotosho and B. J. Abiodun, "A numerical study of moisture build-up and rainfall over West Africa," Meteorological Applications, vol. 14, no. 3, pp. 209-225, 2007.

[38] N. S. Diffenbaugh, "Atmosphere-land cover feedbacks alter the response of surface temperature to $\mathrm{CO}_{2}$ forcing in the western United States," Climate Dynamics, vol. 24, no. 2-3, pp. 237251, 2005.

[39] K. H. Cook and E. K. Vizy, "Effects of twenty-first-century climate change on the Amazon rain forest," Journal of Climate, vol. 21, no. 3, pp. 542-560, 2008.

[40] C. A. Alo and G. Wang, "Potential future changes of the terrestrial ecosystem based on climate projections by eight general circulation models," Journal of Geophysical Research G, vol. 113, no. 1, Article ID G01004, 2008.

[41] S. Janicot, G. Caniaux, F. Chauvin et al., "Intraseasonal variability of the West African monsoon," Atmospheric Science Letters, vol. 12, pp. 58-66, 2011. 
[42] E. A. B. Eltahir and C. L. Gong, "Dynamics of wet and dry years in West Africa," Journal of Climate, vol. 9, no. 5, pp. 10301042, 1996.

[43] B. Fontaine, P. Roucou, and P.-A. Monerie, "Changes in the African monsoon region at medium-term time horizon using 12 AR4 coupled models under the Alb emissions scenario," Atmospheric Science Letters, vol. 12, no. 1, pp. 83-88, 2011.

[44] N. Philippon, L. Jarlan, N. Martiny, P. Camberlin, and E. Mougin, "Characterization of the interannual and intraseasonal variability of West African vegetation between 1982 and 2002 by means of NOAA AVHRR NDVI data," Journal of Climate, vol. 20, no. 7, pp. 1202-1218, 2007.

[45] M. Claussen, "On multiple solutions of the atmospherevegetation system in present-day climate," Global Change Biology, vol. 4, no. 5, pp. 549-559, 1998.

[46] R. A. Betts, P. M. Cox, and F. I. Woodward, "Simulated responses of potential vegetation to doubled- $\mathrm{CO}_{2}$ climate change and feedbacks on near-surface temperature," Global Ecology and Biogeography, vol. 9, no. 2, pp. 171-180, 2000.

[47] A. L. Steiner, J. S. Pal, S. A. Rauscher et al., "Land surface coupling in regional climate simulations of the West African monsoon," Climate Dynamics, vol. 33, no. 6, pp. 869-892, 2009. 

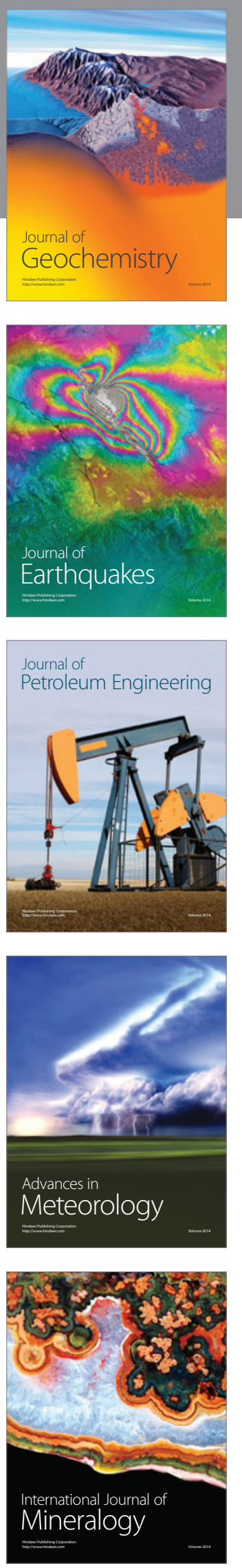
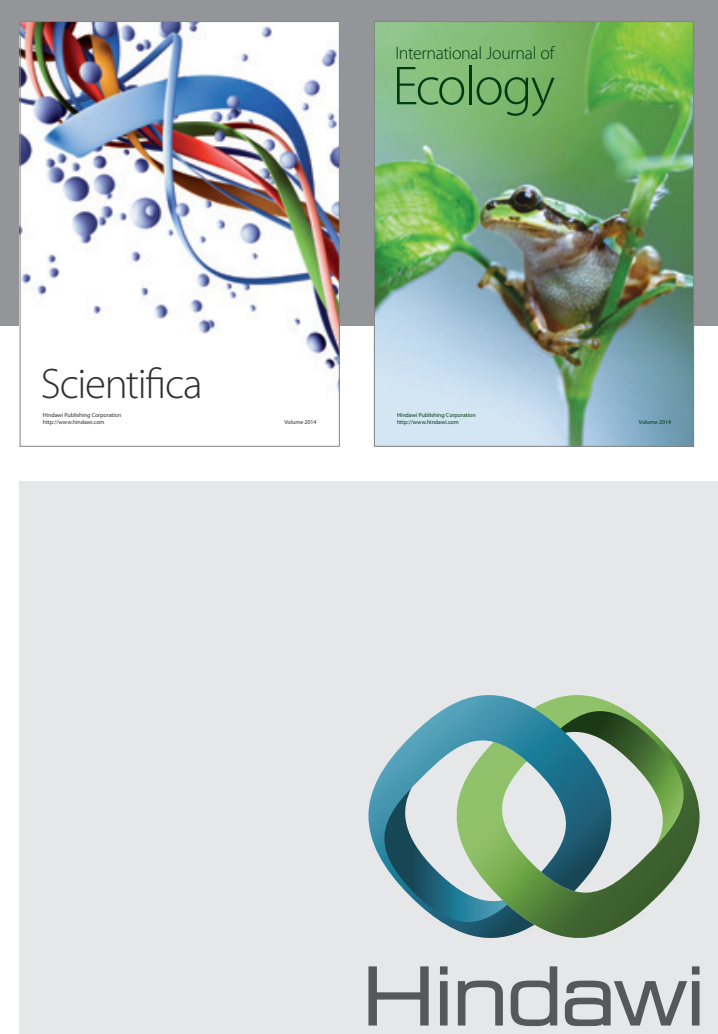

Submit your manuscripts at http://www.hindawi.com
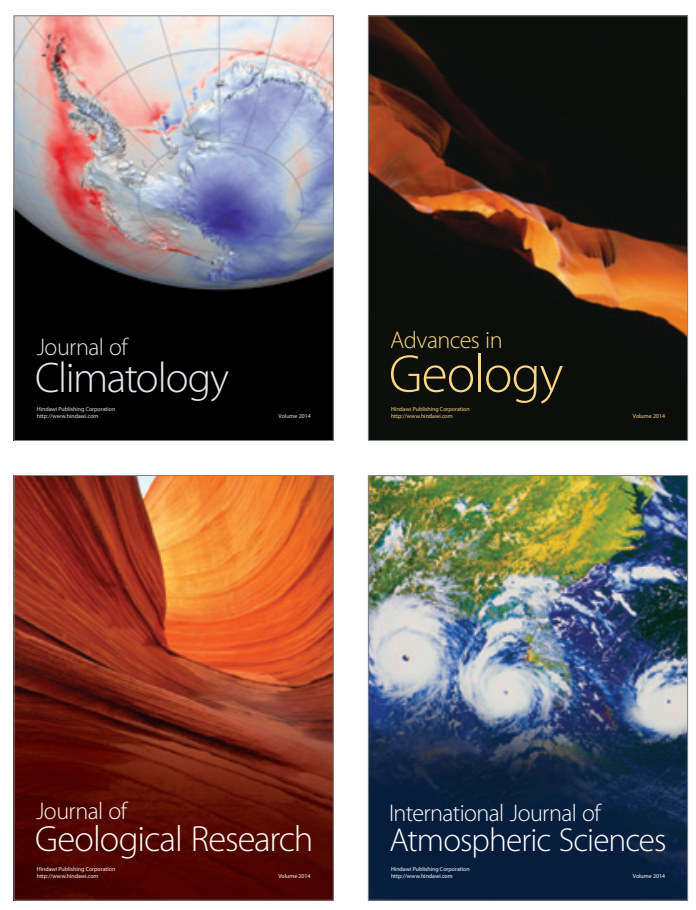
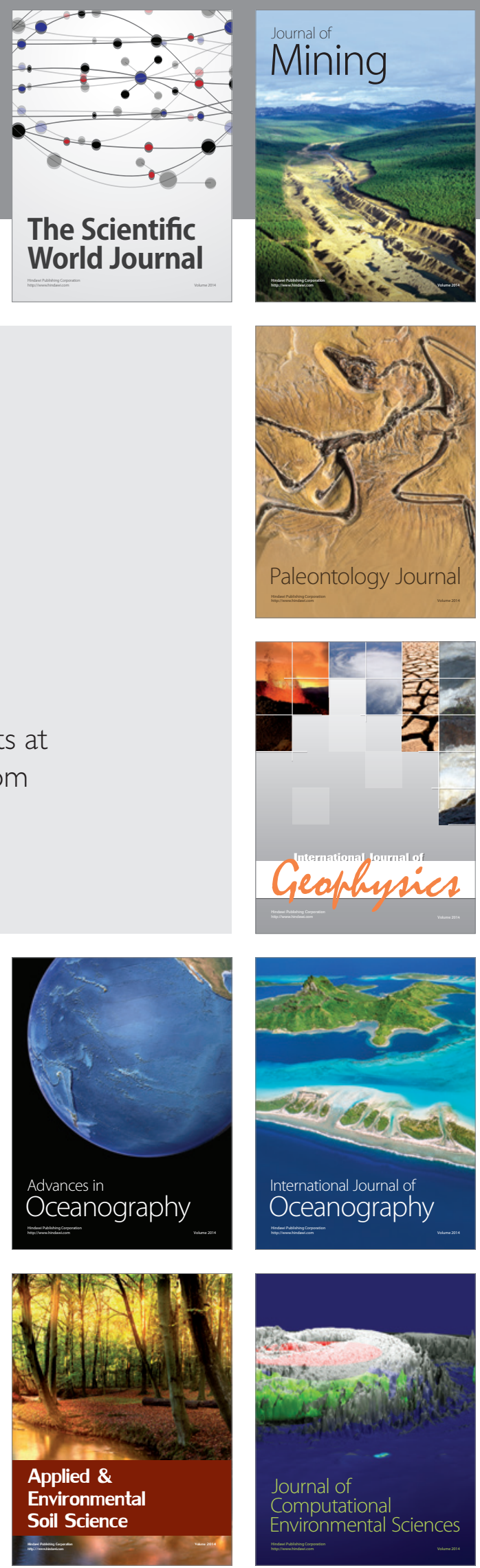